\title{
Influence of Alfalfa Residue and Different-source Biochars on the Chemical Properties of A Saline-sodic Soil
}

\author{
Zahra Noori $^{1}$, Mohammad-Amir Delavar ${ }^{2}$, Yaser Safari ${ }^{3 *}$ \\ ${ }^{1}$ Graduated MSc. of Soil Science, College of Agriculture, University of Zanjan, Iran. \\ ${ }^{2}$ Associate Professor of Soil Science, Department of Soil Sciences, Collage of Agriculture, University of Zanjan, Iran. \\ ${ }^{3}$ Assistant Professor of Soil Science, Department of Soil Sciences, Collage of Agriculture, Shahrood University of \\ Technology, Iran.yaser.safari@shahroodut.ac.ir
}

\begin{abstract}
A pot experiment was done aimed to improve the chemical properties of a saline-sodic soil using individual application of alfalfa residue and two biochars, produced from sugarcane bagasse and walnut shell and their concomitant application with gypsum, aluminum sulfate and mixture of these two chemical amendments. Organic and chemical amendments were added to the soil at the weighting ratio of $2.5 \%$ and as the soil gypsum requirement, respectively. After two months of incubation, soil samples were measured for soil $\mathrm{pH}$, electrical conductivity (EC) and sodium adsorption ratio (SAR) and the results were analyzed by SPSS software applying ANOVA. The results showed that organic amendments caused a reduction in soil $\mathrm{pH}$ and enhanced soil EC and SAR; whereas addition of gypsum and/or aluminum sulfate with biochars intensified their regulatory effects. It can be concluded that application of walnut-shell biochar with mixture of gypsum and aluminum sulfate to the saline-sodic soils has the best efficiency to reclaim the chemical soil properties. Soil leaching, as a supplementary procedure, however, is necessary to complete the improving effects of organic and/or chemical application to the soil.

Keywords: Arid Soils; Salt-affected Soil; Soil Reclamation; Sugarcane Bagasse; Walnut Shell
\end{abstract}

\section{Introduction}

Soil salinization is considered as one of the main environmental problems threatening agricultural productivity worldwide (Chaganti and Crohn, 2015). The most important problems in salt-affected soils that may reduce the soil productivity and finally resulted in a decline in plant production include: possible toxicity of dominant anions or cations, nutrient deficiency at high $\mathrm{pH}$ values, surface crust and soil dispersion, physico-structural soil deterioration, high osmotic tension and water deficiency, and organic matter losses (Amini et al., 2015). Reclamation of salt-affected soils is a profitable management strategy on natural-resources conservation to sustainably meet the increasing requirement for food around the world (Mao, et al., 2016). Among the different existing ways for reclaiming of salt-affected soils, application of organic and chemical amendments to the soil, leaching and phyto-reclamation have been more successfully used by researchers (Amini et al., 2015). These methods are individually or subsequently used and selection of the best one may depend on specific considerations, such as local soil properties, economic issues and more important, environmental aftermaths.

Chemical amendments having sulfate ion, like gypsum and aluminum sulfate, are considered as the most prevalent salt-affected soil ameliorators that addition to lowering the soil $\mathrm{pH}$, simplify the replacement of exchangeable sodium with divalent cations, like calcium (Makoi and Ndakidemi, 2007). As an environmental-compatible, nutrient-rich organic amendment, biochars are recently more and more considered by researchers for reclaiming and rehabilitating soils with different unfavorable physicochemical properties. Biochar is a carbonaceous organic material and produced by slow pyrolysis of a vast range of biomasses under limited oxygen conditions (Chaganti and Crohn, 2015).

Copyright (C) 2018 Zahra Noori et al.

doi: 10.24294/nrcr.v1i4.525

EnPress Publisher LLC.This work is licensed under the Creative Commons Attribution-NonCommercial 4.0 International License (CC BY-NC 4.0).

http://creativecommons.org/licenses/ by/4.0/ 
Prior studies have indicated that different biochars have positively influenced the salt-affected soils (Wu et al., 2014; Chaganti et al., 2015; Yue et al., 2016; Sappor et al., 2017; Schultz et al., 2017). The biochar efficiency, however, are mainly influenced by their raw materials, biochar-production requirements and general properties of target environment (Luo et al., 2016).

Iran is situated in an arid to semi-arid region and most of the agricultural lands are suffered from insufficient water, capable to transfer the soluble salts to the lower soil layers; thus, excessive salt accumulation in surface layers of the soil is among the most important abiotic stresses that limit crop production in Iran (Rassouli et al., 2013). On the other hand, regarding the natural resources conservation lows, proper management of crop residues in the current outdated conventional agricultural systems in vast areas of the country, is an important challenge for land managers. Therefore, it seems that biochar production and its application in problematic soils may be considered as a win-win procedure. The present study was done aimed to improve the chemical properties of a saline-sodic soil using individual application of alfalfa residue and two biochars, produced from sugarcane bagasse and walnut shell and their concomitant application with gypsum, aluminum sulfate and mixture of these two chemical amendments.

\section{Materials and Methods}

The studied saline-sodic soil was collected from a non-cultivated area located on the west of Hamedan Province, Northwest Iran (Figure 1). Soil was crushed and passed through a 2-mm sieve and 1 kilogram accurately weighted to put in plastic pots. Meanwhile, soil $\mathrm{pH}$ in saturated paste and electrical conductivity (EC) in saturated extract were measured. Soluble sodium concentration $\left(\mathrm{Na}^{+}\right)$and calcium and magnesium $\left(\mathrm{Ca}^{2+}\right.$ and $\left.\mathrm{Mg}^{2+}\right)$ were also measured using a Flame-photometer (PFP7 Jenway) and atomic absorption spectrometer (Varian AA20), respectively (Page et al., 1982). Soil Sodium Adsorption Ratio (SAR) was calculated using below equation.

$$
\mathrm{SAR}=\sqrt{\frac{\mathrm{Na}^{+}}{\frac{\mathrm{Ca}^{2+}+\mathrm{Mg}^{2+}}{2}}}
$$

where $\mathrm{Na}^{+}, \mathrm{Ca}^{2+}$, and $\mathrm{Mg}^{2+}$ are respective soluble cation concentrations given in meq/lit.

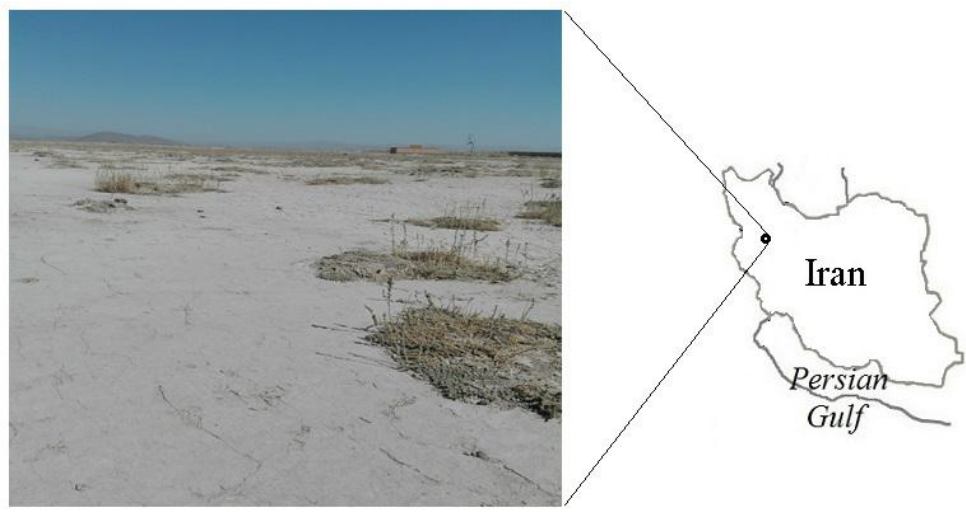

Figure 1; Sampling location of the studied saline-sodic soil in Northwest of Iran.

The applied organic amendments in the present study include alfalfa residue and two biochars, which were produced from sugarcane bagasse and green walnut shell. Raw materials were crushed and passed through a 2-mm sieve and pyrolyzed at $400{ }^{\circ} \mathrm{C}$ under oxygen limited conditions for 3 hours in an industrial furnace. Produced biochars and alfalfa residue were accurately weighted to prepare the weighting ratio of $2.5 \%$ (ratio of organic amendments weight to soil weight). Moreover, chemical treatments including gypsum as the soil gypsum requirement, aluminum sulfate as the equivalent of soil gypsum requirement, and mixture of gypsum and aluminum sulfate, each one as half of the equivalent of soil gypsum requirement were prepared. Thus, 12 treatments along with control were obtained, as shown in Table 1 and the experiment was conducted in three replications using factorial experiment in completely randomized design. All control and treatments were incubated for two months at moisture content of field capacity. 


\begin{tabular}{lll}
\hline Chemical amendment & Organic amendment & Symbol \\
\hline- & - & $\mathrm{C}$ \\
\hline- & Sugarcane-Bagasse Biochar & SBB \\
& Walnut-Shell Biochar & WSB \\
& Alfalfa Residue & AR \\
\hline \multirow{3}{*}{ Gypsum } & Sugarcane-Bagasse Biochar & G-SBB \\
& Walnut-Shell Biochar & G-WSB \\
& Alfalfa Residue & G-AR \\
\hline \multirow{3}{*}{ Aluminum Sulfate } & Sugarcane-Bagasse Biochar & AlS-SBB \\
& Walnut-Shell Biochar & AlS-WSB \\
& Alfalfa Residue & AlS-AR \\
\hline
\end{tabular}

Table 1. The experimental design along with applied organic and chemical amendments

After conducting the experiments, chemical properties of soils including, pH, EC and SAR were measured. Data were analyzed using one-way analyses of variance (ANOVA) and significant differences between the treatment means were analyzed using Duncan's test in SPSS at 95\% significance level $(\mathrm{P}<0.05)$.

\section{Results and Discussion}

\subsection{General soil properties}

As shown in Table 2, the studied soil has negligible organic carbon storage and is classified as a saline-sodic soil, based on the prevalent criteria (Amini et al., 2015). Having relatively high calcium carbonate, the soil is grouped as a carbonated soil, which is the dominant property of the Iranian soils (Safari et al., 2015).

\begin{tabular}{llllll}
\hline Soil property & $\mathrm{pH}$ & $\mathrm{EC}(\mathrm{dS} / \mathrm{m})$ & SAR & OC $(\%)$ & Calcium carbonate $(\%)$ \\
\hline Value & 9.13 & 8.04 & 22.6 & 0.21 & 37.9 \\
\hline
\end{tabular}

Table 2. Selected soil chemical properties

Table 3 shows the result of one-way ANOVA. Analyses of variance for selected soil properties revealed a significant difference for all properties at 95\% significance level $(\mathrm{P}<0.01)$.

\begin{tabular}{lllll}
\hline & $\mathrm{DF}$ & $\mathrm{pH}$ & $\mathrm{EC}$ & $\mathrm{SAR}$ \\
\hline Amendment & 3 & $0.83^{* *}$ & $35.29^{* *}$ & $77.10^{* *}$ \\
Biochar or alfalfa residue & 2 & $6.70^{* *}$ & $649.97^{* *}$ & $1312.31^{* *}$ \\
Amendment*Biochar & 6 & $0.44^{* *}$ & $9.39^{* *}$ & $85.13^{* *}$ \\
Error & 26 & 0.01 & 2.77 & 0.80 \\
Coefficient of variation & - & 1.22 & 18.54 & 3.01 \\
\hline
\end{tabular}

Table 3. Results of one-way ANOVA

\subsection{Soil pH}

Simple effects of the studied treatments on soil $\mathrm{pH}$ are presented in Figure 2. Addition of organic amendments without chemical materials led to a significant decrease of soil $\mathrm{pH}$; whereas concomitant application of organic and chemical amendments lowered soil pH more efficiently. Relative solution of gypsum in the water existing in soil 
porosity resulted in a significant increase in calcium concentration; thus the replaced exchangeable hydrogen $(\mathrm{H}+)$ by calcium may enter the soil solution and led to $\mathrm{pH}$ reduction (Qadir et al., 2003). On the other hand, breaking up of aluminum sulfate in soil may lead to sulfuric acid formation, which declining the activity if carbonate and bicarbonate ions, caused a significant soil $\mathrm{pH}$ decrease.
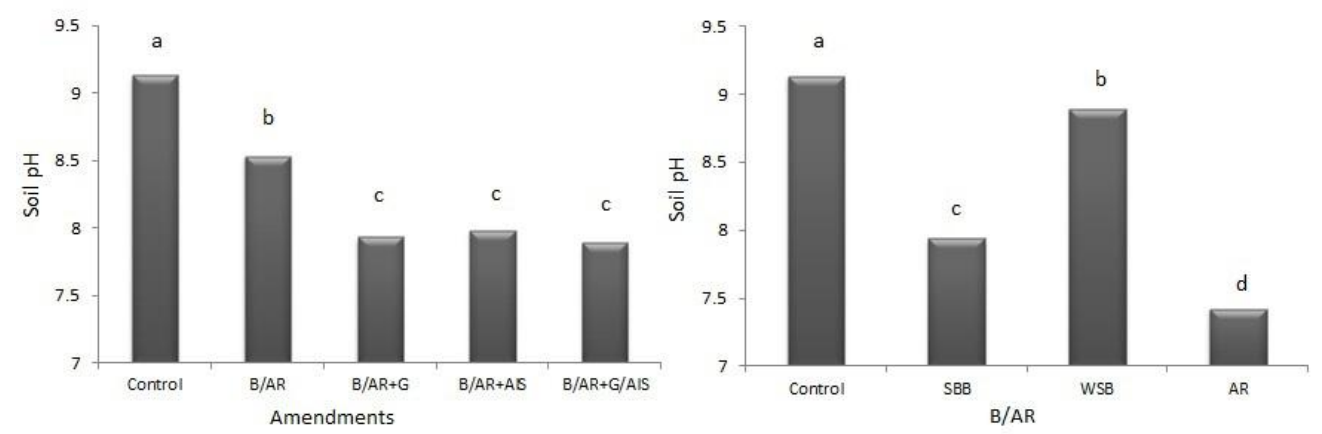

Figure 2; Simple effects of organic and chemical treatments (left) and biochar or crop residues type (right) on soil pH.

Addition of organic amendments to the soil may stimulate the microbial activity. Thus, the carbon dioxide partial pressure will be increased during organic matter decomposition in soil and cause development of pH-reducing conditions. Among organic amendments, AR most efficiently reduced soil $\mathrm{pH}$ but WSB had the least positive effect on $\mathrm{pH}$, due to its alkaline nature. In accordance with these findings, Wu et al. (2014) reported that furfural residue is more efficient than its biochar in reducing $\mathrm{pH}$ in a treated saline soil. Reciprocal effects of organic and chemical amendments on soil $\mathrm{pH}$ are presented in Table 4.

\begin{tabular}{|c|c|c|c|c|c|c|c|c|c|c|c|c|c|}
\hline \multirow{2}{*}{$\begin{array}{l}\text { Amendmen } \\
\mathrm{B} / \mathrm{AR}\end{array}$} & \multirow{2}{*}{$\frac{\mathrm{C}}{-}$} & \multicolumn{3}{|l|}{ B/AR } & \multicolumn{3}{|c|}{$\mathbf{B} / \mathbf{A R}+\mathbf{G}$} & \multicolumn{3}{|c|}{ B/AR+AIS } & \multicolumn{3}{|c|}{$\mathrm{B} / \mathrm{AR}+\mathrm{G} / \mathrm{AIS}$} \\
\hline & & SBB & WSB & AR & SBB & WSB & AR & SBB & WSB & $\mathrm{AR}$ & SBB & WSB & $\mathrm{AR}$ \\
\hline $\mathrm{pH}$ & $9.13 b$ & $8.12 d$ & $9.99 \mathrm{a}$ & $7.48 \mathrm{f}$ & $7.90 \mathrm{e}$ & $8.46 c$ & $7.44 \mathrm{f}$ & $7.90 \mathrm{e}$ & $8.62 c$ & $7.40 \mathrm{f}$ & $7.83 \mathrm{e}$ & $8.49 c$ & $7.34 f$ \\
\hline
\end{tabular}

Means followed by the same letters are not significantly different $(\mathrm{P}<0.05)$.

Table 4. The interactive effects of organic and chemical amendments on soil $\mathrm{pH}$

Compared with the application of organic amendments-alone, simultaneous addition of organic and chemical amendments to the soil more efficiently reduced soil $\mathrm{pH}$ (Table 4). The most $\mathrm{pH}$ reduction was observed in the soil treated by $\mathrm{AR}+\mathrm{G} / \mathrm{AlS}$. Sappor et al. (2017) found that during organic matter decomposition in soil, anions existing in soil colloid surfaces tend to be declined. It also has been reported that biochar capability for reducing salt-affected soil pH mainly influenced by the types of raw materials (Schultz et al., 2017).

\subsection{Soil EC}

Simple effects of the studied treatments on soil EC are presented in Figure 3. Application of organic amendments-alonereduced soil EC but their concomitant application with chemical materials increased soil EC (Fig 3). Increased sulfate (So42-) and calcium (Ca2+) concentration in soil electrolyte due to gypsum and aluminum sulfate decomposition in soil resulted in higher EC values. On the other hand, EC reduction in soils treated by organic amendments may be attributed to the adsorption of some soluble ions by functional groups existing at the AR or biochar surface.
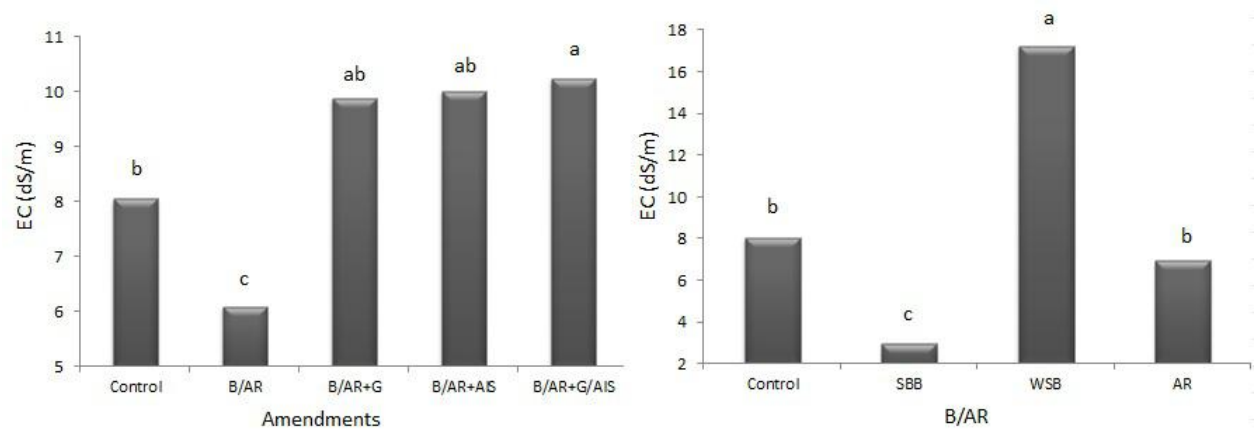
Figure 3. Simple effects of organic and chemical treatments (left) and biochar or crop residues type (right) on soil EC

Comparing the effects of SBB, WSB and AR on soil EC revealed that WSB significantly increased EC values, whereas SBB and AR caused a significant and negligible EC reduction, respectively (Fig 3). This observation clearly indicates that the type of raw materials used to biochar production highly control the biochar function in the soil. Yue $e t$ al. (2016) have stated that soil texture, salinity and sodicity level of studied soils and type of raw materials are the main factors that control the salt-affected soil reclamation efficiency by biochar application. Reciprocal effects of organic and chemical amendments on soil EC are presented in Table 5.

\begin{tabular}{|c|c|c|c|c|c|c|c|c|c|c|c|c|c|}
\hline \multirow{2}{*}{$\begin{array}{l}\text { Amendmen } \\
\mathrm{B} / \mathrm{AR}\end{array}$} & \multirow{2}{*}{ C } & \multicolumn{3}{|c|}{ B/AR } & \multicolumn{3}{|c|}{$\mathrm{B} / \mathbf{A R}+\mathbf{G}$} & \multicolumn{3}{|c|}{ B/AR+AIS } & \multicolumn{3}{|c|}{ B/AR+G/AIS } \\
\hline & & SBB & WSB & AR & SBB & WSB & AR & SBB & WSB & AR & SBB & WSB & AR \\
\hline $\mathrm{EC}(\mathrm{dS} / \mathrm{m})$ & $8.0 \mathrm{c}$ & $1.0 \mathrm{f}$ & $11.7 \mathrm{~b}$ & $5.5 \mathrm{cde}$ & $3.7 \mathrm{def}$ & $17.5 \mathrm{a}$ & $8.5 \mathrm{c}$ & 4.0def & $19.4 \mathrm{a}$ & $6.6 \mathrm{~cd}$ & $3.2 \mathrm{ef}$ & $20.3 \mathrm{a}$ & $7.2 \mathrm{c}$ \\
\hline
\end{tabular}

Means followed by the same letters are not significantly different $(\mathrm{P}<0.05)$.

Table 5. The interactive effects of organic and chemical amendments on soil EC

$\mathrm{SBB}-$ alone and $\mathrm{WSB}+\mathrm{G} / \mathrm{AlS}$ application led to the most reduction and increase in EC values, respectively (Table 5). Schultz et al. (2017) reported that biochar-alone application to a sodic soil had no effect on soil EC but contemporary application of biochar with gypsum significantly increased soil EC. It should be noted that although in the present study, most of applied treatments resulted in higher EC compared with un-amended soil (C), but leaching at the end of the experiment may simply reduce EC values to normal range.

\subsection{Soil SAR}

Simple effects of the studied treatments on soil SAR are presented in Figure 4.
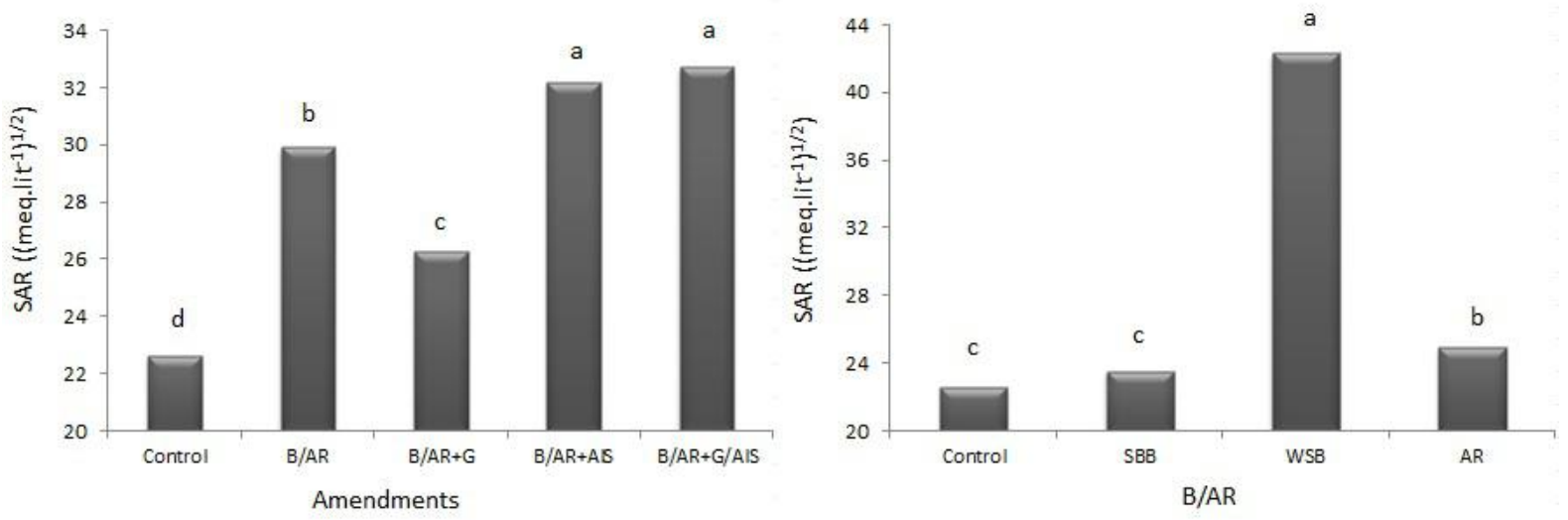

Figure 4; Simple effects of organic and chemical treatments (left) and biochar or crop residues type (right) on soil SAR.

As shown in Figure 4, organic and chemical amendments significantly enhanced soil SAR. This observation indicates that soluble sodium concentration relative to total concentration of calcium and magnesium in amended soil has been increased due to the changes of soil ionic composition. Now that all applied amendments, especially chemical ones, are considered as calcium-rich sources, soil calcium and magnesium concentration has been increased compared with un-amended soil. On the other hand, the applied amendments have no considerable sodium amount. Consequently, the observed SAR increase at the present study may be attributed to the entrance of exchangeable sodium to solution phase which is formerly replaced by calcium and/or magnesium. Although the unfavorable SAR values have been aggravated that way, but it actually indicates that applied amendments successfully discharged soil exchangeable sites from sodium. In accordance with these findings, Wong et al. (2009) reported that addition of gypsum and crop residue to a saline-sodic soil effectively removed exchangeable sodium and thus, exchangeable sodium percentage significantly reduced. Nevertheless, it was observed that soil SAR did not considerably change. Reciprocal effects of organic and chemical amendments on soil SAR are presented in Table 6. 


\begin{tabular}{l|l|lll|lll|lll|ll|ll|l}
\hline Amendme & $\mathbf{C}$ & B/AR & & \multicolumn{3}{|l|}{ B/AR+G } & \multicolumn{2}{|l|}{ B/AR+AIS } & & \multicolumn{2}{|l}{ B/AR+G/AIS } \\
\hline B/AR & - & SBB & WSB & AR & SBB & WS & AR & SBB & WS & AR & SBB & WS & AR \\
\hline SAR & $22.6 \mathrm{e}$ & $23.7 \mathrm{~d}$ & 35.3 & 30.7 & 21.6 & 35.4 & 21.8 & $23.8 \mathrm{~d}$ & 49.0 & $23.8 \mathrm{~d}$ & 25.1 & 49.6 & $23.4 \mathrm{~d}$ \\
\hline
\end{tabular}

Means followed by the same letters are not significantly different $(\mathrm{P}<0.05)$.

Table 6. The interactive effects of organic and chemical amendments on soil SAR

Among the applied amendments, WSB+G/AlS resulted in the highest soil SAR values (Table 6). Schultz et al. (2017) reported that biochar application to a sodic soil slightly enhanced soil calcium concentration; whereas application of gypsum-alone and gypsum with biochar led to significant SAR increase. As soil pH and soil EC, SAR changes at the present study is severely influenced by the type of raw material used to biochar production. Notwithstanding, soil leaching and analyses of chemical properties after leaching should be done to have a more accurate judgment about the biochar efficiency in salt-affected soil reclamation.

\section{Conclusion}

Organic amendments, including alfalfa residue and two biochars produced from green walnut shell and sugarcane bagasse caused a reduction in soil $\mathrm{pH}$ and enhanced soil EC and SAR. Addition of gypsum, aluminum sulfate and mixture of these two chemical amendments along with biochars intensified their regulatory effects. The different effects of two studied biochars on saline-sodic soil properties indicates that biochar efficiency in improving soil quality is mainly influenced by the type of raw material used to biochar production. Although soil leaching, as a supplementary procedure is needed to complete the improving effects of organic and/or chemical application to the soil, but it can be concluded that application of walnut-shell biochar with mixture of gypsum and aluminum sulfate to the saline-sodic soils has a good ability to reclaim the chemical soil properties.

\section{References}

1. Amini S, Ghadiri H, Chen Ch, et al. Salt-affected soils, reclamation, carbon dynamics, and biochar: a review. Journal of Soils and Sediments 2015; 16(3): 939-953.

2. Chaganti VN, Crohn DM. Evaluating the relative contribution of physiochemical and biological factors in ameliorating a saline-sodic soil amended with composts and biochar and leached with reclaimed water. Geoderma. 2015; 259-260: 45-55.

3. Chaganti VN, Crohn DM, Simunek J. Leaching and reclamation of a biochar and compost amended saline-sodic soil with moderate SAR reclaimed water. Agricultural Water Management. 2015; 158: 255-265.

4. Luo X, Liu G, Xia Y, et al. Use of biochar-compost to improve properties and productivity of the degraded coastal soil in the Yellow River Delta, China. Journal of Soils and Sediments. 2016; 17(3): 780-789.

5. Makoi JHJR, Ndakidemi PA. Reclamation of sodic soils in Rundugai village, Hai District, Kilimanjaro Region, Tanzania, using locally available organic and inorganic resources. African Journal of Biotechnology. 2007; 26(16): 1926-1931.

6. Mao Y, Li X, Dick WA, et al. Remediation of saline-sodic soil with flue gas desulfurization gypsum in a reclaimed tidal flat of southeast China. Journal of Environmental Sciences. 2016; 45: 224-232.

7. Page, A.L. Method of soil analysis. Part 2: Chemical and microbiological properties. Soil Science Society of American Madison, Wisconsin, USA, 1982.

8. Qadir M, Steffens D, Yan F. and Schubert, S. Sodium removal from a calcareous saline-sodic soil through leaching and plant uptake during phytoremediation. Land Degradation and Development. 2003; 14(3): 301-307.

9. Rasouli F, Kiani-Pouya A, Karimian N. Wheat yield and physico-chemical properties of a sodic soil from semi-arid area of Iran as affected by applied gypsum. Geoderma. 2013; 193-194: 246-255.

10. Safari Y, Delavar MA, Zhang Ch. Esfandiarpour-Boroujeni, I. and Owliaie, H.R. The influences of selected soil properties on $\mathrm{Pb}$ availability and its transfer to wheat (Triticum aestivum L.) in a polluted calcareous soil. Environmental Monitoring and Assessment. 2015; 187(12). DOI: 10.1007/s10661-015-5001-9.

11. Sappor DK, Osei BA, Ahmed MR. Reclaiming sodium affected soil: the potential of organic amendments. International Journal of Plant and Soil Science. 2017; 16(2): 1-11.

12. Schultz E, Chatterjee A, DeSutter T, et al. Sodic soil reclamation potential of gypsum and biocharadditiions: influence on physicochemical properties and soil respiration. Communications in Soil Science and Plant Analyses. 2017; 48(15): 1792-1803.

13. Wong VNL, Dalal RC, Greene RSB. Carbon dynamics of sodic and saline soils following gypsum and organic 
material additions: A laboratory incubation. Applied Soil Ecology 2009; 41: 29-40.

14. Wu Y, Xu G, Shao HB. Furfural and its biochar improve the general properties of a saline soil. Solid Earth. 2014; 5: 665-671.

15. Yue Y, Guo WN, Lin QM, et al. Improving salt leaching in a simulated saline soil column by three biochars derived from rice straw (Oryza sativa L.), sunflower straw (Helianthus annuus), and cow manure. Journal of Soil and Water Conservation. 2016; 71(6): 467-475. 